\title{
MECHANICAL PROPERTIES OF RECYCLED AGGREGATE CONCRETE WITH DEFORMED STEEL RE-BAR
}

\author{
Yongjae Kim \\ Department of Civil \& Environmental Engineering, Hanyang University, Korea. \\ Jongsung Sim \\ Department of Civil \& Environmental Engineering, Hanyang University, Korea. \\ Cheolwoo Park \\ Department of Civil Engineering, Kangwon National University, Korea., tigerpark@kangwon.ac.kr
}

Follow this and additional works at: https://jmstt.ntou.edu.tw/journal

Part of the Civil and Environmental Engineering Commons

\section{Recommended Citation}

Kim, Yongjae; Sim, Jongsung; and Park, Cheolwoo (2012) "MECHANICAL PROPERTIES OF RECYCLED AGGREGATE CONCRETE WITH DEFORMED STEEL RE-BAR," Journal of Marine Science and Technology. Vol. 20: Iss. 3, Article 5. DOI: $10.51400 / 2709-6998.1804$

Available at: https://jmstt.ntou.edu.tw/journal/vol20/iss3/5

This Research Article is brought to you for free and open access by Journal of Marine Science and Technology. It has been accepted for inclusion in Journal of Marine Science and Technology by an authorized editor of Journal of Marine Science and Technology. 


\title{
MECHANICAL PROPERTIES OF RECYCLED AGGREGATE CONCRETE WITH DEFORMED STEEL RE-BAR
}

\author{
Yongjae Kim ${ }^{1}$, Jongsung Sim ${ }^{1}$, and Cheolwoo Park ${ }^{2}$
}

Key words: recycled aggregate concrete, bond strength, compressive strength, elastic modulus, replacement ratio.

\begin{abstract}
This study investigates fundamental properties of the recycled aggregate which was produced through recent hi-technique of recycling. In addition, the mechanical properties of the concrete that was made by the recycled aggregate were compared to the concrete made of natural aggregate. The primary objective of this study was to characterize the concrete-rebar bonding properties of the recycled aggregate concrete.

The recycled aggregate concrete showed about $18 \%$ decreased bond strength as compared to the natural aggregate concrete. The current prediction equation of bond strength suggested by the design specification does not consider this decreased bond strength by the use of the recycled aggregate. Therefore, this study suggests an equation for predicting the bond strength for the recycled aggregate concrete considering the recycled aggregate replacement ratio and consequent compressive strength reduction.
\end{abstract}

\section{INTRODUCTION}

Aggregate is the essential basic construction material affecting the properties of concrete and taking approximately $70 \%$ of volume of Portland cement concrete and over $90 \%$ of asphalt concrete, respectively [5]. Such aggregate performs an important function when it is mixed with relatively expensive binders such as cement or bituminous materials, and enables economical construction. It also takes a role of maintaining the structure's stability against physical and chemical effects of cement.

In the past, generally in Korea, high quality river-run gravel and sand were collected and used in the construction industry but their amounts produced and used became very significant

Paper submitted 02/10/11; revised 08/15/11; accepted 11/21/11. Author for correspondence: Cheolwoo Park (e-mail: tigerpark@kangwon.ac.kr).

${ }^{I}$ Department of Civil \& Environmental Engineering, Hanyang University, Korea.

${ }^{2}$ Department of Civil Engineering, Kangwon National University, Korea. due to its limits in reserves and ecosystem disturbance [11]. In these days, peoples are collecting the construction aggregate even from EEZ (Exclusive Economic Zone) of sea and tries to make the aggregate collecting plant equipment larger. However, it is expected that the natural resource of aggregate will run out within 30 to 40 years [8].

Recycled aggregate is a also aggregate produced through recycling process of waste concrete. It used to be employed for low value added use including land reclamation, filling, sub-base material for road and concrete secondary products manufacturing. However with a recent advancement of technology for processing the waste concrete it is possible to produce recycled aggregate as of similar quality as the natural aggregate. Therefore, the potential of its usage for a structural member, high-value purposes, has grown much higher [12].

It has been known that the workability of recycled aggregate concrete is lower than the natural aggregate concrete. Compressive strength and elastic modulus of recycled aggregate concrete are also lower about $15 \%$ to $20 \%$ than the natural aggregate concrete $[9,10]$. Bond strength of recycled aggregate concrete reduces about $10 \%$ to $35 \%$ [6]. When only coarse aggregate is replaced with the recycled the bond strength dropped about 5\% to $15 \%$, and when both coarse and fine aggregate were replaced, about $20 \%$ [1, 2]. It was also reported that the replacement ratio was up to $30 \%$, bending and shear strengths were maintained to a comparable level but over 30\% the strengths were reduced significantly [13].

Only few researches are available on the bond strength of recycled aggregate concrete with varying replacement ratios. Therefore, this research investigates the bonding characteristics of recycled aggregate concrete with varying replacement ratios along with the fundamental physical properties.

\section{EXPERIMENT SUMMARY}

This study is intended to understand characteristics of recycled aggregate concrete and its bonding performance to the deformed re-bar and compare the bond strength to a natural aggregate concrete. Concrete specimens for two different mix proportions with varying levels of replacement of recycled coarse aggregate and recycled fine aggregate were made while diameter of deformed re-bar for the two specimens was kept 
Table 1. Experimental variables.

\begin{tabular}{|c|c|c|c|}
\hline \multirow{2}{*}{ Specimen } & \multicolumn{2}{|c|}{ Mixed aggregate } & \multirow{2}{*}{$\begin{array}{l}\text { Deformed re-bar } \\
\text { diameter }(\mathrm{mm})\end{array}$} \\
\hline & Coarse aggregate & Fine aggregate & \\
\hline $\mathrm{NN}$ & Natural $100 \%$ & Natural $100 \%$ & 19 \\
\hline $\mathrm{RN}$ & Recycled $100 \%$ & Natural $100 \%$ & 19 \\
\hline RR30 & Recycled $100 \%$ & $\begin{array}{c}\text { Recycled, } \\
30 \% \text { replaced }\end{array}$ & 19 \\
\hline RR60 & Recycled $100 \%$ & $\begin{array}{l}\text { Recycled, } \\
60 \% \text { replaced }\end{array}$ & 19 \\
\hline RR & Recycled $100 \%$ & $\begin{array}{c}\text { Recycled, } \\
100 \% \text { replaced }\end{array}$ & 19 \\
\hline
\end{tabular}

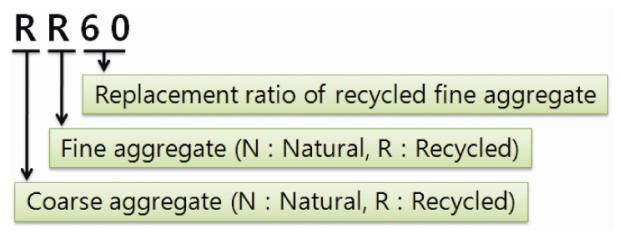

Fig. 1. Details of specimen description.

the same. The bond strengths was measured through the pullout test of the prepared specimens.

\section{Variables}

According to results of previous researches, the characteristics of recycled aggregate concretes vary considerably depending upon the quality and replacement level of recycled aggregate used. In this experiment, recycled aggregate produced by advanced recycling method was used. The replacement level of aggregate was set as the major variable, so that the mix proportions were established with variations in the percentage of coarse and fine aggregate replacement.

The coarse aggregate used in the study showed about the similar properties as the natural aggregate. Therefore, $100 \%$ recycled coarse aggregate is used instead of fractioning it in mix proportions.

In addition, researches show that if a percentage level of replacement of fine aggregate exceeds $60 \%$, there is significant reduction in the concrete quality and performance. Hence, the replacement percentage for fine aggregate were set as $30 \%$, $60 \%$ and $100 \%$.

Deformed re-bar of $19 \mathrm{~mm}$ diameter was used in the specimens. Fig. 1 shows an detailed description of specimen name used in this study. Table 1 addresses the specimen variables.

\section{Preparation of Specimens}

It is typical to use a pull-out specimen as shown in the upper part in Fig. 2 (KS F 2441). However, in our study, we modified the traditional pull-out test specimen to a different shape as shown in the lower part in Fig. 2 but maintained the bonded length of $15 \mathrm{~cm}$. This modification may minimize the localized deformation, i.e. elongation, and slippage that can cause wrong reading of the deformation. In addition, the used speci-
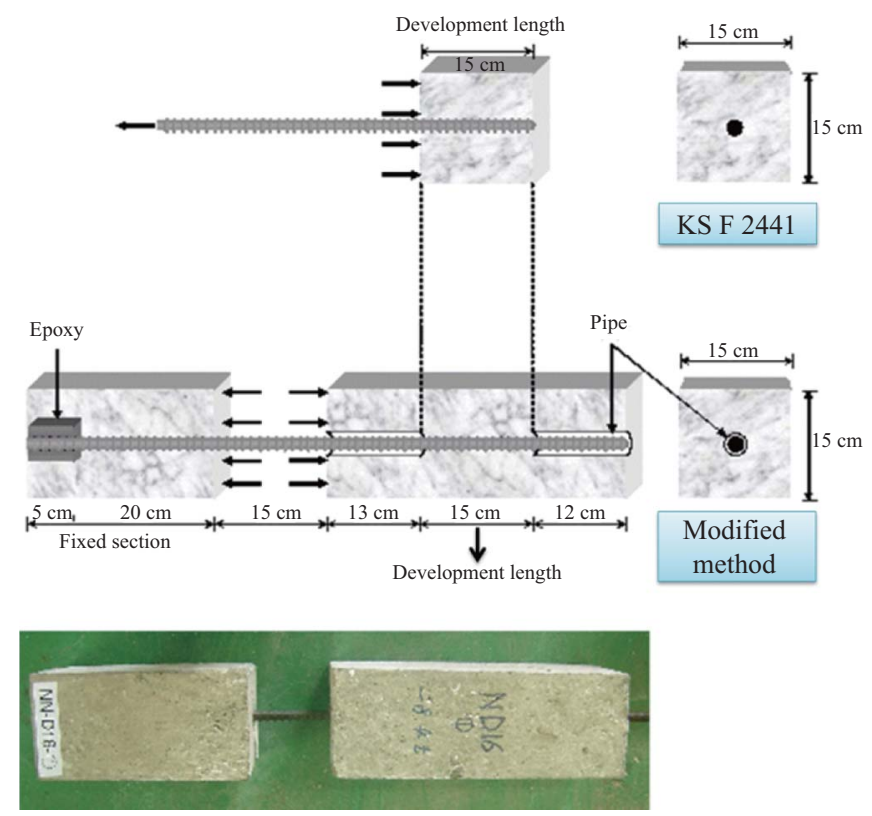

Fig. 2. Bond strength pull-out test specimen.

men can allow variation of bonded length if desired and the first unbounded area of $13 \mathrm{~cm}$ will provide evenly distributed stress though the bonded area rather the traditional specimen bring an excessive stress concentration at the contact area to the experimental jig.

\section{Materials}

The cement used was Type I Portland cement. Table 2 and Table 3 describe physical properties of the recycled and natural aggregate used in this experiment.

\section{Mix Proportions}

Table 4 shows the mix proportions for each variable. The primary mix proportion was based on the natural concrete mix and no extra alteration was made with the addition of recycled aggregate. Replacement level of recycled aggregate is based on the volume.

\section{Specimen Curing}

Compressive strength and elastic modulus were measured using the cylinder specimens, which were cured under water for 28 days. The pull-out specimens were also cured under water but all the exposed surface of the steel re-bar was covered with an oil in order to minimize corrosion. It was then wet cured in the normal temperature using curing blanket which kept it consistently wet.

\section{Bond Strength Measurement}

This experiment employed a modified pull-out testing scheme in which deformed re-bar is not directly pulled out. Additional metal parts were prepared and the right-hand side in Fig. 3 where re-bar fixing epoxy bulb was embedded was pulled out. In order to minimize the anticipated errors which 
Table 2. Properties of coarse aggregate.

\begin{tabular}{|c|c|c|c|c|c|c|}
\hline & \multicolumn{3}{|c|}{$\begin{array}{l}\text { Specification for recycled } \\
\text { coarse aggregate }\end{array}$} & \multirow{2}{*}{$\begin{array}{l}\text { Used recycled } \\
\text { coarse aggregate }\end{array}$} & \multirow{2}{*}{$\begin{array}{c}\text { Specification } \\
\text { for natural } \\
\text { coarse aggregate }\end{array}$} & \multirow{2}{*}{$\begin{array}{c}\text { Used natural } \\
\text { coarse aggregate }\end{array}$} \\
\hline & Class 1 & Class 2 & Class 3 & & & \\
\hline water absorption ratio (\%) & Less than 3.0 & Less than 5.0 & Less than 7.0 & 1.82 & Less than 3.0 & 0.47 \\
\hline density & \multicolumn{3}{|c|}{ greater than 2.2} & 2.61 & More than 2.5 & 2.64 \\
\hline abrasion loss (\%) & \multicolumn{3}{|c|}{ Less than 40} & 21.5 & Less than 40 & 24.1 \\
\hline solid volume percentage (\%) & \multicolumn{3}{|c|}{ Greater than 55} & 60.3 & Greater than 55 & 55.4 \\
\hline
\end{tabular}

Table 3. Properties of fine aggregate.

\begin{tabular}{|c|c|c|c|c|c|}
\hline \multirow{2}{*}{} & \multicolumn{2}{|c|}{ Specification for recycled fine aggregate } & $\begin{array}{c}\text { Used recycled } \\
\text { fine aggregate }\end{array}$ & $\begin{array}{c}\text { Specification for } \\
\text { natural fine aggregate }\end{array}$ & $\begin{array}{c}\text { Used natural } \\
\text { fine aggregate }\end{array}$ \\
\cline { 2 - 5 } & Class 1 & Class 2 & 4.55 & Less than 3.0 & 1.16 \\
\hline water absorption ratio (\%) & Less than 5.0 & Less than 10.0 & 2.43 & Greater than 2.5 & 2.61 \\
\hline density & \multicolumn{2}{|c|}{ Greater than 2.2 } & - & Greater than 53 & - \\
\hline solid volume percentage (\%) & \multicolumn{2}{|c|}{ Greater than 53 } \\
\hline
\end{tabular}

Table 4. Mix Proportion (unit: kgf/ $/ \mathrm{m}^{3}$ ).

\begin{tabular}{|c|c|c|c|c|c|c|c|c|}
\hline \multirow{2}{*}{ Variable } & \multirow{2}{*}{ Water } & \multirow{2}{*}{ Cement } & \multicolumn{2}{|c|}{ Fine Aggregate } & \multicolumn{2}{|c|}{ Coarse Aggregate } & \multirow{2}{*}{ H.R.W.A. } & \multirow{2}{*}{ A.E. } \\
\cline { 3 - 8 } & & & Natural & Recycled & Natural & Recycled & & 0.4 \\
\hline NN & 189.10 & 580.49 & 661.74 & 0 & 851.37 & 0 & 0.42 & 0.4 \\
\hline RN & 189.10 & 580.49 & 661.74 & 0 & 0 & 841.70 & 4.4 & 0.022 \\
\hline RR30 & 189.10 & 580.49 & 463.22 & 184.83 & 0 & 841.70 & 4.4 & 0.022 \\
\hline RR60 & 189.10 & 580.49 & 264.70 & 369.66 & 0 & 841.70 & 4.4 & 0.022 \\
\hline RR & 189.10 & 580.49 & 0 & 616.10 & 0 & 841.70 & 4.4 & 0.022 \\
\hline
\end{tabular}

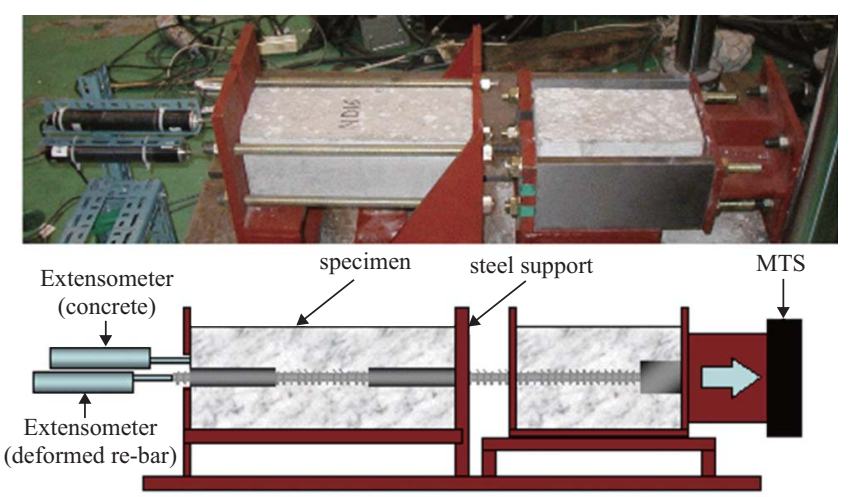

Fig. 3. Bond strength testing scheme.

could occur due to deformation of metal parts left-hand side, the steel support and other fixtures left-hand side were fixed to the bottom of floor using bolts. Only the concrete part on the right-hand side was pulled.

Loading equipment was the MTS actuator with a capacity of $250 \mathrm{kN}$ and the loading was strain-controlled at $0.5 \mathrm{~mm} / \mathrm{min}$ per the experimental specifications.

\section{TEST RESULTS}

\section{Basic Characteristics of Recycled Aggregate Concrete}

1) Slump and Air Content
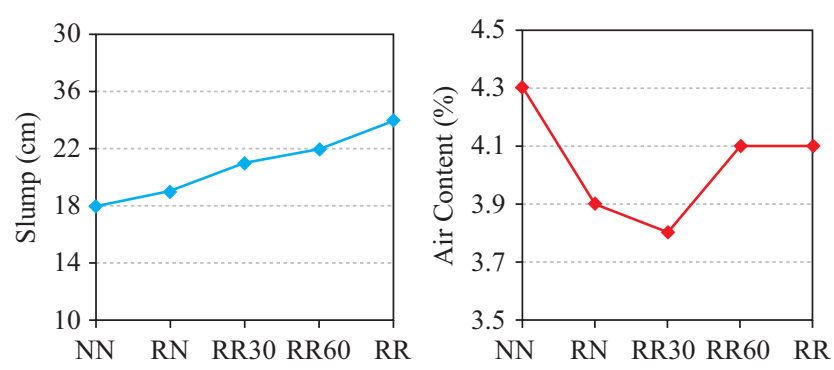

Fig. 4. Slump and air content.

The result of measurements of the slump and air with varying replacement level of recycled aggregate concrete is shown in Fig. 4.

It can be seen that by replacing the natural aggregate with recycled aggregate, the slump value increased while the air content reduced up to a certain point and then increased slightly. The increment of slump may be due to the grain shape originated by the production process. Crushed stone used as natural aggregate had rough and angular shape because of the crushing process. The recycled coarse aggregate was mainly river run gravel which had round shape due to wear and tear in the crusher. This difference in the shape of coarse aggregate may have contributed to the workability improvement. The workability increased as the fine recycled aggregate replacement ratio increased. This may be due to the additional fine particles from the recycled fines. 


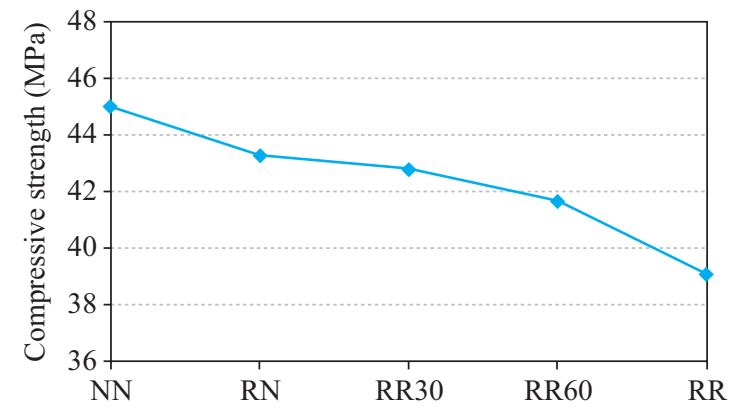

Fig. 5. Compressive strength.

Air content decreased with $100 \%$ recycled coarse aggregate and up to $30 \%$ of recycled fines. However with greater than $60 \%$ of the recycled fine aggregate the air content increased slightly. The included additional fine particles may helped the internal air void within the mixture.

\section{2) Compressive Strength}

The results of compressive strength measurement is shown in Fig. 5.

When only the coarse aggregate was replaced with the recycled the compressive strength decreased about $2 \mathrm{MPa}$. As the fine aggregate replacement ratio increased the compressive strength kept decreasing. Especially when the recycled fine aggregate replacement was over $60 \%$ the strength drop was significant. The strength drop with the recycled can be attributed to the remained mortar on the surface of the recycled aggregate, cracks in the aggregate itself (which could occur during the crushing) and the original aggregate's strength etc. From, the observations, it is recommended that the fine aggregate should better be replaced with the recycled less than $60 \%$ in the consideration of compressive strength.

\section{3) Elastic Modulus}

Elastic modulus was measured by attaching a strain gauge on to the surface of the cylinder specimens. Based on the obtained stress-strain curves, elastic modulus was determined. In addition, by using the measured compressive strength and unit weight, the elastic modulus was calculated following the equation for the comparison purposes.

$$
E=0.077 m_{c}^{1.5} \sqrt[3]{f_{c k}}
$$

Where $m_{c}$ is the unit weight of concrete and $f_{c k}$ is the measured compressive strength.

Table 5 shows both the measured and calculated elastic modulus.

Similar to the results of the compressive strength, it was obvious that the elastic modulus decreased with the increase of the replacement ratio as shown in Table 5. However, the calculated values are much higher than the measured. From this comparison, it is not recommended to use the currently available equation for the calculation of the elastic modulus.
Table 5. Elastic modulus.

\begin{tabular}{|c|c|c|c|}
\hline Variable & $\begin{array}{c}\text { Compressive } \\
\text { strength (MPa) }\end{array}$ & $\begin{array}{c}\text { Measured elastic } \\
\text { modulus (MPa) }\end{array}$ & $\begin{array}{c}\text { Calculated elastic } \\
\text { modulus (MPa) }\end{array}$ \\
\hline NN & 45.0 & 24,185 & 29,836 \\
\hline RN & 43.3 & 20,440 & 29,417 \\
\hline RR30 & 42.8 & 17,981 & 29,292 \\
\hline RR60 & 41.7 & 20,000 & 28,870 \\
\hline RR & 39.1 & 16,516 & 28,325 \\
\hline
\end{tabular}

Table 6. Calculations of bond strength.

\begin{tabular}{|c|c|}
\hline Equation & Bond strength equation \\
\hline Direct calculation & $\tau_{\max }=\frac{P_{\max }}{O \cdot l_{d}}$ \\
\hline CEB-FIP MC90 & $\tau_{\max }=2.0 \sqrt{f_{c k}}$ \\
\hline ACI 318-08 & $\tau_{\max }=5.91 \frac{\sqrt{f_{c k}}}{d_{b}}$ \\
\hline Orangun & $\tau_{\max }=\left[0.2652 \times\left(1.2+\frac{3 c}{d_{b}}+\frac{50 d_{b}}{l_{d}}\right)\right] \times \sqrt{f_{c k}}$ \\
\hline MacGregor & $\tau_{\max }=0.59 \sqrt{f_{c k}}\left(\frac{c}{d_{b}}-0.5\right)$ \\
\hline
\end{tabular}

Therefore, for the recycled aggregate concrete, an appropriate calculation equation for elastic modulus should be developed.

\section{Bond Strength Characteristics of Recycled Aggregate Concrete}

The measured bond strengths were described in Table 7 and compared with the variables in Fig. 6. For the further analysis of the bond strength characteristics, four additional bond strength equations were considered in the study, as shown in Table 6. Actually the four additional equations were developed for natural aggregate concrete and are from CEB-FIP MC90, ACI 318-08, Orangun correlation [7] and MacGregor [4]. They all directly depending on the compressive strength of concrete, $f_{c k}$, developed or embedded length of re-bar, $l_{d}$ and the diameter, $d_{b}$.

For the concrete with only natural aggregate, the MacGregor's and CEB-FIP's equations developed almost coincided results with the experiments but the rest of two equations, ACI and Orangun, significantly underestimated the bond strength. The test results shows a decreased bond strength as the recycled aggregate content increased. However, the four equations did not take account of the bond strength reduction due to the addition of the recycled aggregate even though they accounted the reduced compressive strength. This is a similar observation of the results of the elastic modulus.

In the occasion of replacing only coarse aggregate with the recycled, there was about $3 \%$ decrease of bond strength and additional replacing $30 \%$ of fines with the recycled, approximately $7 \%$ decrease while replacing the whole quantity, 
Table 7. Result of bond strength assessment.

\begin{tabular}{|c|c|c|c|c|c|c|}
\hline Parameter & $\begin{array}{c}\text { Compres-sive } \\
\text { strength (MPa) }\end{array}$ & $\begin{array}{c}\text { Bond strength by } \\
\text { test (MPa) }\end{array}$ & $\begin{array}{c}\text { CEB-FIP MC90 } \\
(\mathrm{MPa})\end{array}$ & $\begin{array}{c}\text { ACI 318-08 } \\
(\mathrm{MPa})\end{array}$ & $\begin{array}{c}\text { Orangun } \\
(\mathrm{MPa})\end{array}$ & $\begin{array}{c}\text { MacGregor } \\
(\mathrm{MPa})\end{array}$ \\
\hline $\mathrm{NN}$ & 45.0 & 13.5 & 13.4 & 6.6 & 9.1 & 13.6 \\
\hline RN & 43.3 & 12.5 & 13.2 & 6.4 & 9.0 & 13.3 \\
\hline RR30 & 42.8 & 12.0 & 13.1 & 6.4 & 9.0 & 13.2 \\
\hline RR60 & 41.7 & 11.4 & 12.8 & 6.3 & 8.8 & 13.0 \\
\hline RR & 39.1 & 9.9 & 12.5 & 6.1 & 8.5 & 12.6 \\
\hline
\end{tabular}

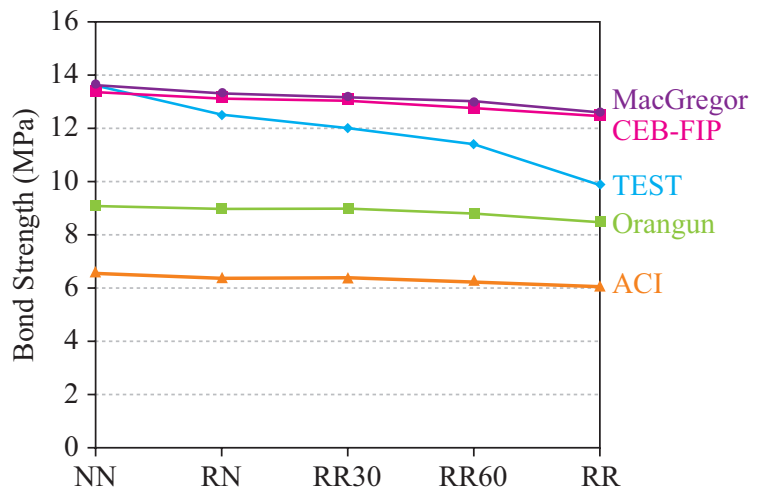

Fig. 6. Comparison of bond strength predictions.

$18 \%$ decrease. This reduction rate with respect to the replacement ratio is shown in Fig. 7.

With the results above, it can be said that even though the recycled aggregate concrete has the same level of compressive strength, the bond strength is not as comparable as that of natural aggregate concrete. There must be various reasons for that difference but no clear answer can be made at this point. However, for the structural design purposes, the test results in the study here can be used to make a correlation between the bond strength and the recycled aggregate with respect to the replacement ratio. The provided correlation is very important as it can be used for the determination of the secured development length of the recycled aggregate concrete.

\section{SUGGESTION OF BOND STRENGTH PREDICTION}

As shown earlier, the prediction equation of natural aggregate concrete is thought to be inappropriate for recycled aggregate concrete. Therefore, this study is about to suggest a new equation suitable to predict bond strength of recycled aggregate concrete. Experimental results shows that in a case of natural aggregate concrete, the bond strength prediction equation by MacGregor seems to be relatively accurate. Therefore, the form of MacGregor equation was adopted as a basic form to calculate the bond strength of recycled aggregate concrete with respect to the replacement ratio. The basic component of the prediction equation by MacGregor's equation is as following Eq. (2).

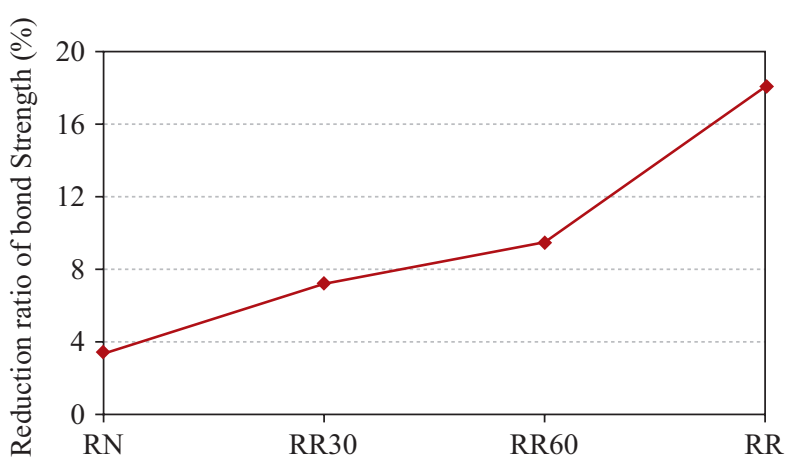

Fig. 7. Reduction rate of bond strength.

$$
\tau_{\max }=\alpha \cdot \sqrt{f_{c k}}\left[\frac{c}{d_{b}}-\beta\right]+\lambda
$$

In this equation, $\alpha$ is the coefficient to calculate the tensile strength of the concrete, and $\beta$ is the coefficient that decides cut-tensile section which the concrete takes care of when the tensile force is applied to the deformed steel re-bar due to load, and $\lambda$ is the coefficient that decides gradient on variations of bond stress with $\alpha, \beta$. Through the analysis it was found that the recycled aggregate concrete changes $\alpha$ from 0.590 into $0.614, \beta$ from 0.50 to 0.55 to adapt the property that has relatively lower tensile strength and small cut-tensile section compared to natural aggregate concrete. Also to apply the property according to changing replacement ratio of recycled aggregate, $\lambda$ became $-0.4203 e^{0.0172 \mathrm{~S}}-0.007 \mathrm{G}[3]$.

Again, the $f_{c k}$, the compression strength, has been replaced with $f_{c k r}$, the recycled aggregate concrete compression strength, to reflect the compressive strength drop of recycled aggregate concrete. The modified equation is suggested as follow.

$$
\tau_{r \max }=0.614 \sqrt{f_{c k r}}\left[\frac{c_{c}}{d_{b}}-0.55\right]-\left(0.4203 e^{0.0172 S}+0.007 G\right)
$$

where,

- $\tau_{r \text { max }}$ : maximum predicted bond stress of recycled aggregate concrete

- $f_{c k r}$ : compressive strength of recycled aggregate concrete according to replacement ratio 
Table 8. Comparison of measured and predicted bond strength.

\begin{tabular}{|c|c|c|c|}
\hline Compressive strength $(\mathrm{MPa})$ & Bond strength by test (MPa) & Prediction equation by MacGregor (MPa) & Suggested equation (MPa) \\
\hline NN & 13.3 & 13.6 & 13.5 \\
\hline RN & 12.5 & 13.3 & 12.5 \\
\hline RR30 & 12.0 & 13.2 & 12.2 \\
\hline RR60 & 11.4 & 13.0 & 11.4 \\
\hline RR & 9.9 & 12.6 & 9.9 \\
\hline
\end{tabular}

- $C_{c}$ : distance from the deformed steel re-bar core to the concrete surface

$\cdot d_{b}$ : diameter of deformed steel re-bar

- $S$ : replacement ratio of recycled fine aggregate

- $G$ : replacement ratio of recycled coarse aggregate

The bond strength predicted by using the suggested Eq. (3) that incorporated the bond characteristics between deformed steel re-bar and recycled aggregate is shown in Table 8. From the comparison it is known that the suggested equation can predict the bond strength of recycled aggregate concrete with varying replacement ratio within a very appropriate error level.

\section{CONCLUSIONS}

Recycled aggregate produced these days has much better performance as comparable to natural aggregate. Engineers begin to use the recycled aggregate for a normal concrete structures. However, its basic characteristics have not been not yet thoroughly investigated. Particularly in order extend the use of the recycled aggregate for the structural concrete, its bonding performance should be fundamentally explored. This research examined the strength and elastic modulus properties with respect to the addition ratio of the recycled aggregate. In addition, through the modified pull-out test its bonding property was studied. From the experimental study herein the conclusions below are drawn.

(1) Recycled aggregate concrete showed an increased workability as the recycled aggregate replacement ratio increased. This may be due to the increased amount of fine particles from the recycling process.

(2) Air content slightly reduced up to $30 \%$ replacement of the recycled fines with $100 \%$ recycled coarse aggregate. With a greater amount of the recycled fines, the air content tended to increase. However the air content did not vary significantly and seemed to be controlled with the addition of air entraining admixture.

(3) Compressive strength decreased when the coarse aggregate was replaced with the recycled. Additional replacement of the fine aggregate reduced the strength as the recycled fines amount increased. When the fine aggregate replacement was greater than $60 \%$ the strength reduction became more significantly. Elastic modulus showed a similar tendency. However the currently available formula for the elastic modulus, which depends on compressive strength, did not properly predict when the recycled aggregate was used.

(4) Bond strength decreased with the increased amount of the recycled aggregate. The bond strength prediction formulas, which relatively accurately calculated for natural aggregate concrete, did not take an account of the addition of the recycled. This study suggested a newly developed bond strength predicting equation conjunctionally considering the addition of the recycled aggregate. The suggested equation relatively close prediction with the variation of the recycled aggregate replacement. The suggested equation can also be used for the calculation of the development length of reinforcing steel, which is the most important structural design criteria.

Based on the structural performance investigated in this study, it is expected that the application of the recycled aggregate can be further extended for the structural concrete members.

\section{REFERENCES}

1. Ajdukiewicz, A. B., "Comparative tests of beams and columns made of recycled aggregate concrete and natural aggregate concrete," Journal of Advanced Concrete Technology, Vol. 5, No. 2, pp. 259-273 (2007).

2. Ajdukiewicz, A. B. and Kliszczewicz, A., "Influence of recycled aggregates on mechanical properties of HS/HPS," Cement \& Concrete Composites, Vol. 24, pp. 269-279 (2002).

3. Kim, Y. J., Bond Characteristics Between Deformed Steel Re-bar and Recycled Aggregate Concrete, Master Thesis, Department of Civil Engineering, Hanyang University, Ansan, Korea (2005).

4. MacGregor, J. G., Reinforced Concrete, 3rd Edition, Prentice-Hall, New Jersey, pp. 290-301 (1997).

5. Metha, P. K. and Monterio, P. J. M., Concrete, 3rd Edition, Mc-Graw-Hill, New York, pp. 253-258 (2006).

6. Nam, S. I., A Study on the Engineering Properties of Recycled Aggregate Concrete, Ph.D. Dissertation, Department of Civil Engineering, Chungnam University, Daejeon, Korea (1995).

7. Orangun, C. O., "Re-evaluation of test data on development length and splices," Proceedings of ACI Journal, Vol. 74, pp. 114-122 (1977).

8. Park, H. G., Jung, K. H., Lim, N. K., Lee, Y. D., Jung, S. J., and Jung, J. Y., "An experimental study on field application of recycled aggregate concrete: Focused on recycled aggregate from underwater crusher by electric impact system," Journal of the Korea Institute of Building Construction, Vol. 3, No. 1, pp. 123-129 (2003).

9. Salem, R. M., Burdette, E. G., and Jackson, N. M., "Freeze-Thaw durability of recycled aggregate concrete," ACI Materials Journal, Vol. 100, 
pp. 216-221 (2003).

10. Salem, R. M., Burdette, E. G., and Jackson, N. M., "Interrelationship of physical properties of concrete made with recycled aggregates," Proceedings of the Transportation Research Board, 82nd Annual Meeting, pp. 1-20 (2001).

11. Seo, C. H. and Kim, B. Y., "An experimental study on the durability of recycled aggregate concrete," Journal of the Korea Concrete Institute,
Vol. 17, No. 3, pp. 385-392 (2005).

12. Song, S. H., Choi, K. S., You, Y. C., Kim, K. H., and Yun, H. D., "Flexural behavior of reinforced recycled aggregate concrete beams," Journal of the Korea Concrete Institute, Vol. 21, No. 4, pp. 431-439 (2009).

13. Tochigi, T., Yosimoto, M., Kiji, D., and Tomita, O., "Influence of quality of recycled aggregate on concrete properties," Journal of Structural and Construction Engineering, Vol. 25, No. 1, pp. 102-109 (2003). 